\title{
RANCANGAN APLIKASI PENDAFTARAN SERVICE PADA PT. ASTRA INTERNATIONAL TBK DAIHATSU BANJARMASIN
}

\author{
Hasanuddin ${ }^{1)}$, Andie ${ }^{2)}$ \\ ${ }^{1}$ Fakultas Teknologi Informasi, Universitas Islam Kalimantan Muhammad Arsyad Al Banjari Banjarmasin \\ Email : hasan.uniska@gmail.com \\ ${ }^{2}$ Fakultas Teknologi Informasi, Universitas Islam Kalimantan Muhammad Arsyad Al Banjari Banjarmasin \\ Email : andina777@gmail.com
}

\begin{abstract}
Abstrack
PT. Astra International Tbk. Daihatsu Indonesia adalah salah satu perusahaan swasta yang terkemuka di Indonesia. Perusahaan ini, diharuskan mempunyai bengkel dengan service center yang bagus, sehingga customer memiliki kepuasan tersendiri pada perusahaan tersebut. PT. Astra International Tbk. Daihatsu Banjarmasin adalah salah satu cabang yang beralamat J1. A. Yani Km. 7.4 Banjarmasin Kalimantan Selatan. Sebenarnya perusahaan sudah memiliki sebuah aplikasi pendaftaran service yang cukup baik, namun masih terdapat kekurangan pada aplikasi. Proses service dimulai dari pelanggan melakukan pendaftaran service mobil pada Service Advisor (SA), selanjutnya mobil diserahkan kepada mekanik dan bagian sparepart untuk pengecekan selanjutnya. Setelah proses service mobil selesai, maka dilanjutkan dengan proses pencucian mobil. Menurut informasi dari angket kepuasan pelanggan, pelanggan yang meninggalkan proses service tidak merasa puas dengan pelayanan service, karena petugas service seringkali lupa tidak melakukan konfirmasi secara langsung bahwa kendaraan telah selesai diservice. Hal ini seringkali terjadi dikarenakan tidak adanya sistem secara otomatis yang dapat melakukan konfirmasi secara langsung dari step posisi kendaraan yang diservice. Seharusnya setiap perubahan data status service akan di sampaikan langsung ke Handphone pelanggan melalui SMS. Jadi pelanggan dapat mengetahui sudah sampai dimana proses service mobilnya masing-masing.
\end{abstract}

Kata kunci: aplikasi, mobil, servis, SMS, web

\section{PENDAHULUAN}

PT. Astra International Tbk. Daihatsu Indonesia adalah salah satu perusahaan swasta yang terkemuka di Indonesia. Perusahaan ini, diharuskan mempunyai bengkel dengan service center yang bagus, sehingga customer memiliki kepuasan tersendiri pada perusahaan tersebut. PT. Astra International Tbk. Daihatsu Banjarmasin adalah salah satu cabang yang beralamat Jl. A. Yani Km. 7.4 Banjarmasin Kalimantan Selatan. Sebenarnya perusahaan sudah memiliki sebuah aplikasi pendaftaran service yang cukup baik, namun masih terdapat kekurangan pada aplikasi.

Proses service dimulai dari pelanggan melakukan pendaftaran service mobil pada Service Advisor (SA), selanjutnya mobil diserahkan kepada mekanik dan bagian sparepart untuk pengecekan selanjutnya. Setelah proses service mobil selesai, maka dilanjutkan dengan proses pencucian mobil. Menurut informasi dari angket kepuasan pelanggan, pelanggan yang meninggalkan proses service tidak merasa puas dengan pelayanan service, karena petugas service seringkali lupa tidak melakukan konfirmasi secara langsung bahwa kendaraan telah selesai diservice. Hal ini seringkali terjadi dikarenakan tidak adanya sistem secara otomatis yang dapat melakukan konfirmasi secara langsung dari step posisi kendaraan yang diservice. Seharusnya setiap perubahan data status service akan di sampaikan langsung ke Handphone pelanggan melalui SMS. Jadi pelanggan dapat mengetahui sudah sampai dimana proses service mobilnya masing-masing. (Rasyidan, et al., 2016)

Oleh karena itu peneliti berencana merancang aplikasi pendaftaran service dengan beberapa keunggulan yaitu ditambahkannya fitur Email Gateway dan SMS Gateway.

\section{METODE PENELITIAN}

Untuk memperoleh data yang diperlukan dalam penyusunan penelitian ini dengan menggunakan metode pengumpulan data sebagai berikut: (Andie, et al., 2019)

a. Wawancara atau interview

Wawancara adalah suatu metode yang digunakan untuk memperoleh data dengan cara mengajukan pertanyaan-pertanyaan secara 
langsung. Dalam hal ini penulis melakukan wawancara dengan pihak perusahaan terutama pada bagian Service Advisor (SA) tentang bagaimana alur penerimaan service.

b. Pengamatan Langsung atau Observasi.

Observasi adalah metode pengumpulan data dengan cara mengamati secara langsung proses pendataan data service di perusahaan tersebut.

c. Studi Pustaka

Studi pustaka adalah suatu metode pengumpulan data dengan menggunakan bukubuku dan pencarian di internet sebagai bahan referensi dalam penulisan laporan dan pembuatan sistem.

\section{Tahapan Pembuatan Sistem}

Dalam pengembangan sistem ini, ada beberapa tahapan yang harus dilakukan. Adapun tahapan tersebut adalah sebagai berikut:

a. Analisa Sistem

Dalam membangun aplikasi ini diperlukan perencanaan yang baik agar dihasilkan sistem yang dapat berjalan optimal. Tahap perencanaan ini terbagi atas 2 yaitu:

1) Menentukan tujuan pembuatan aplikasi

Tujuan penelitian ini adalah agar mempermudah Service Advisor (SA) dalam menginput data service dan juga mempermudah penyampaian informasi data status service langsung ke masing-masing pelanggan

2) Menentukan siapa yang akan menjadi pemakai

Perancangan aplikasi ini diperuntukkan untuk bagian Service Advisor atau bagian penerimaan dan pendaftaran service.

b. Perancangan Sistem

Proses perancangan yang baik diperlukan untuk pembuatan program tak terkecuali dalam pembuatan aplikasi yang baik. Perancangan sistem secara terperinci, dilakukan dengan cara:

1) Rancangan Menu

Berikut rancangan menu yang dibuat untuk aplikasi pendaftaran servis ini.

Tabel 1. Rancangan Menu

\begin{tabular}{|ccc|}
\hline No & Menu Utama & Sub Menu \\
\hline 1 & Login & \\
\hline 2 & Home & \\
\hline 3 & Pendaftaran & \\
\hline 4 & Data Pendaftaran & \\
\hline 5 & Data Pembantu & Type Mobil \\
\hline
\end{tabular}

\begin{tabular}{|c|c|c|}
\hline 6 & & Paket Servis \\
\hline 7 & & Admin \\
\hline 8 & Laporan & Harian \\
\hline 9 & & Bulanan \\
\hline 10 & & Tahunan \\
\hline 11 & Logout & \\
\hline
\end{tabular}

2) Rancangan Database

Database dibuat menggunakan database MySQL dengan nama database "daihatsu" dan terdiri dari 4 tabel utama, yaitu: (Subekti, 1997)

Tabel 2. Database Tabel admin

\begin{tabular}{|ccc|}
\hline Field & Type & Null \\
\hline id & int(11) & No \\
\hline nm_admin & $\operatorname{varchar}(100)$ & No \\
\hline username & $\operatorname{varchar}(100)$ & No \\
\hline password & $\operatorname{varchar}(100)$ & No \\
\hline
\end{tabular}

Tabel 3. Database Tabel paket

\begin{tabular}{|ccc|}
\hline Field & Type & Null \\
\hline id & int(11) & No \\
\hline paket & $\operatorname{varchar}(200)$ & No \\
\hline ket & text & No \\
\hline
\end{tabular}

Tabel 4. Database Tabel servis

\begin{tabular}{|ccc|}
\hline Field & Type & Null \\
\hline nama & int(11) & No \\
\hline telpon & varchar(100) & No \\
\hline alamat & varchar(15) & No \\
\hline nopol & text & No \\
\hline type_mobil & varchar(10) & No \\
\hline paket_servis & varchar(200) & No \\
\hline biaya_paket & bigint(20) & No \\
\hline tambahan & $\operatorname{text}$ & Yes \\
\hline biaya_tambahan & bigint(20) & Yes \\
\hline total & bigint(20) & No \\
\hline catatan_user & $\operatorname{text}$ & Yes \\
\hline catatan_teknisi & text & Yes \\
\hline catatan_admin & text & Yes \\
\hline waktu_kembali & varchar(50) & No \\
\hline waktu_servis & varchar(50) & No \\
\hline admin & varchar(100) & No \\
\hline status & varchar(20) & No \\
\hline
\end{tabular}


Tabel 5. Database Tabel type_mobil

\begin{tabular}{|ccc|}
\hline Field & Type & Null \\
\hline id & $\operatorname{int}(11)$ & No \\
\hline type_mobil & $\operatorname{varchar}(100)$ & No \\
\hline
\end{tabular}

3) Relasi Antar Tabel

Berikut relasi antar tabel yang terbentuk untuk aplikasi pendaftaran servis ini.

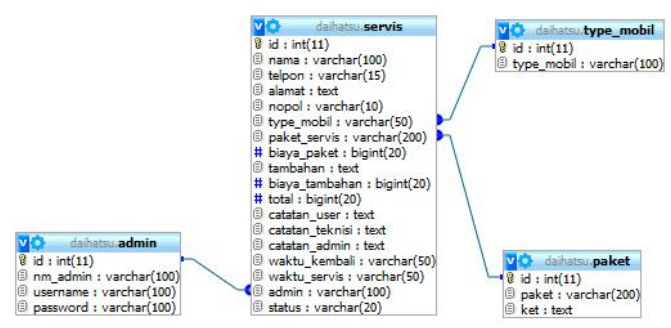

Gambar 1. Relasi Antar Tabel

4) Diagram Konteks

5) Data Flow Diagram (DFD)

6) Rancangan Tampilan

7) Rancangan Output dan Laporan

8) Pembuatan Program

Pembuatan aplikasi pendaftaran service ini dibuat menggunakan bahasa pemrograman PHP dan MySQL sebagai pengelola databasenya. (Peranginangin \& Kasiman, 2006)

c. Testing Aplikasi

Pada tahap ini, dilakukan uji terhadap sistem yang telah selesai dibuat dengan menggunakan modem dan satu buah laptop server, setiap proses pendaftaran dan perubahan status service di uji apakah sistem sudah berhasil mengirim SMS secara otomatis dan sesuai dengan hasil yang diharapkan.

\section{HASIL DAN PEMBAHASAN}

Pada Aplikasi Pendaftaran Servis ini terdapat halaman utama yaitu halaman administrator, halaman ini di kelola oleh admin yaitu Service Advisor (SA). Sebelum masuk aplikasi admin harus login terlebih dahulu, berikut tampilan dari halaman login admin.

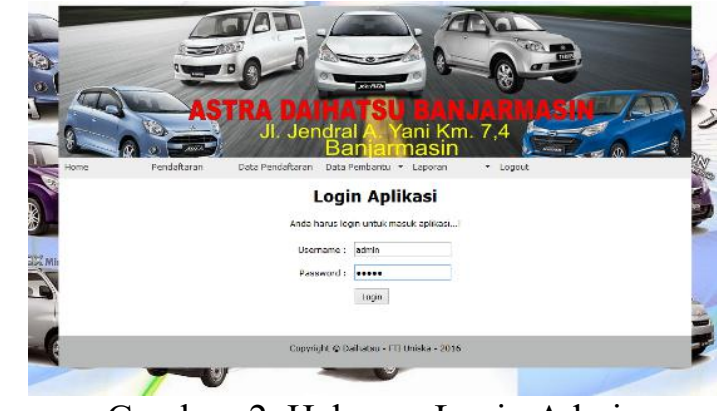

Gambar 2. Halaman Login Admin

Setelah berhasil masuk halaman login, admin harus memasukkan username dan passwordnya, apabila user akun cocok maka admin dapat menggunakan aplikasi, apabila salah maka admin kembali diarahkan ke halaman login. Pada aplikasi terdapat beberapa menu yang dapat digunakan oleh admin. Berikut akan dibahas kegunaan dari masing-masing halaman.

\section{a. Halaman Home}

Setelah berhasil login maka admin akan di arahkan ke halaman home. Berikut tampilan dari halaman home.

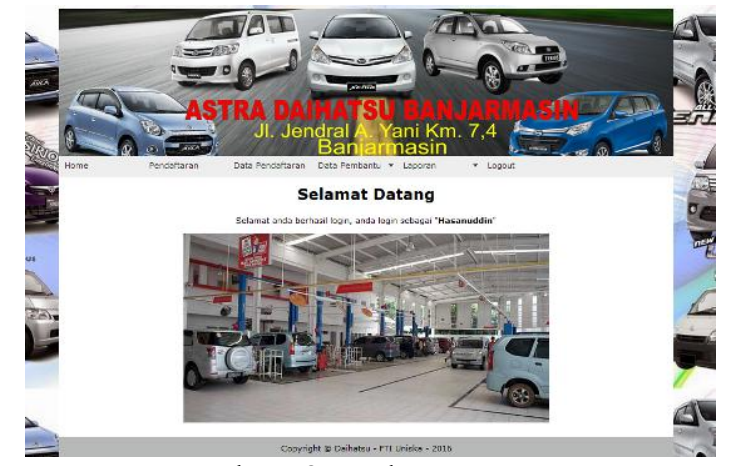

Gambar 3. Halaman Home

\section{b. Halaman Pendaftaran Servis}

Pada halaman ini admin dapat menambahkan data servis baru, ini adalah halaman utama dari aplikasi ini. Berikut tampilannya. 


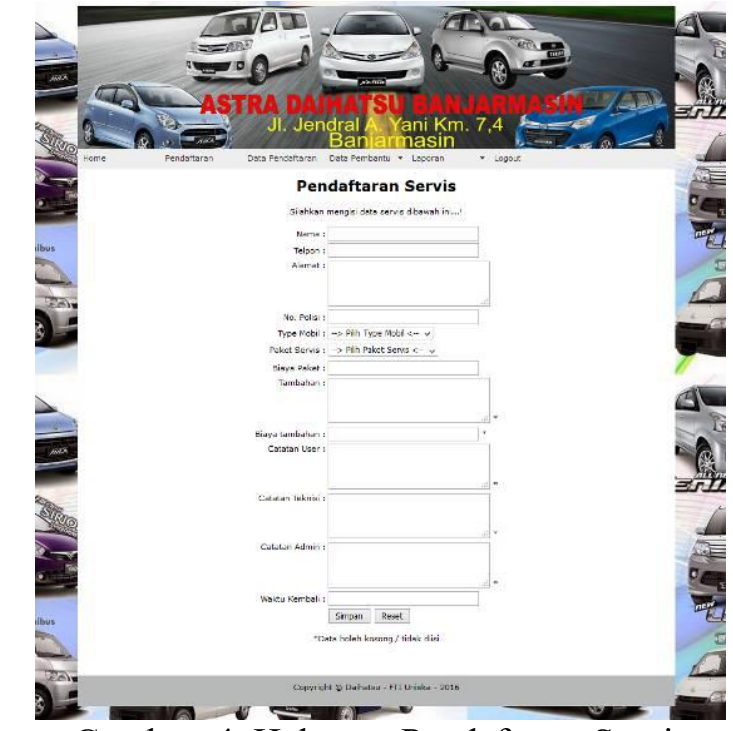

Gambar 4. Halaman Pendaftaran Servis

\section{c. Halaman Data Pendaftaran}

Setelah admin memasukkan data pendaftaran, maka akan langsung ke halaman data pendaftaran, pada halaman ini admin dapat mengedit, melihat, maupun menghapus data pendaftaran. Apabila admin mengedit data pendaftaran, misalnya merubah status pendaftaran dari New ke Selesai, maka disitulah terjadi proses SMS ke pelanggan yang memberitahukan bahwa servis sudah selesai. Berikut tampilannya.

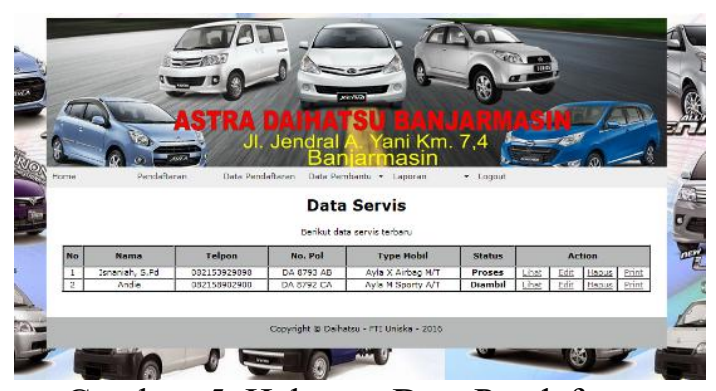

Gambar 5. Halaman Data Pendaftaran

\section{d. Halaman Data Type Mobil}

Pada halaman ini admin dapat memanajemen data type mobil baik menambahkan, mengedit maupun menghapus data type mobil. Berikut tampilannya.

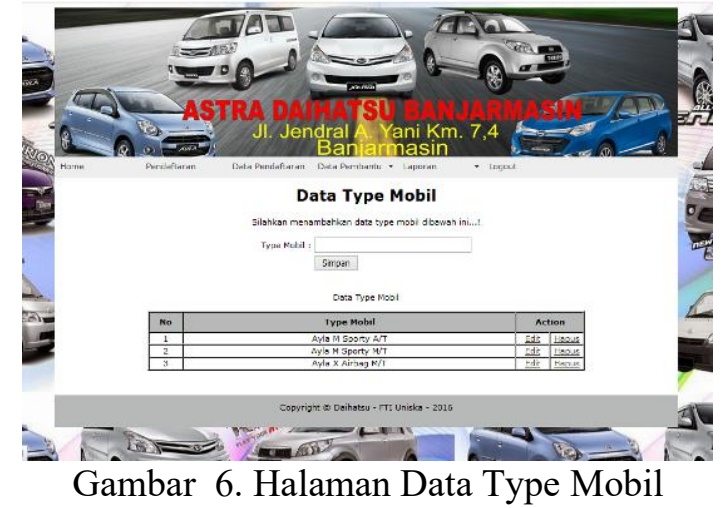

e. Halaman Data Paket Servis

Pada halaman ini admin dapat memanajemen data paket servis baik menambahkan, mengedit maupun menghapus data paket servis. Berikut tampilannya.

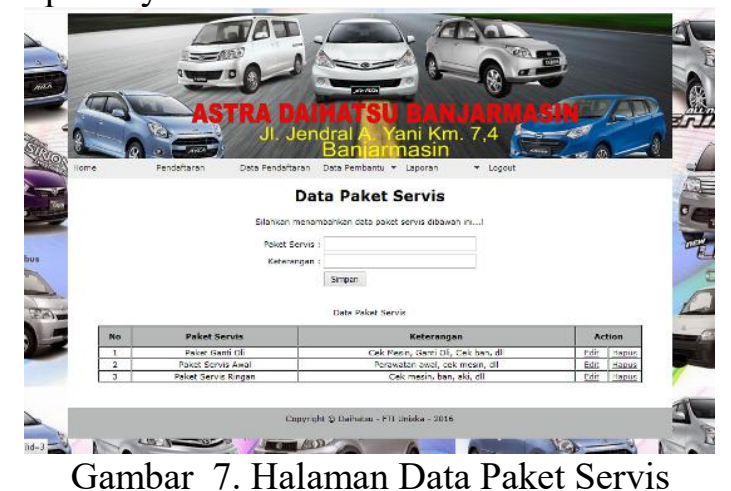

\section{f. Halaman Manajemen Admin}

Pada halaman ini admin dapat memanajemen data admin baik menambahkan maupun mengedit data admin. Berikut tampilannya.

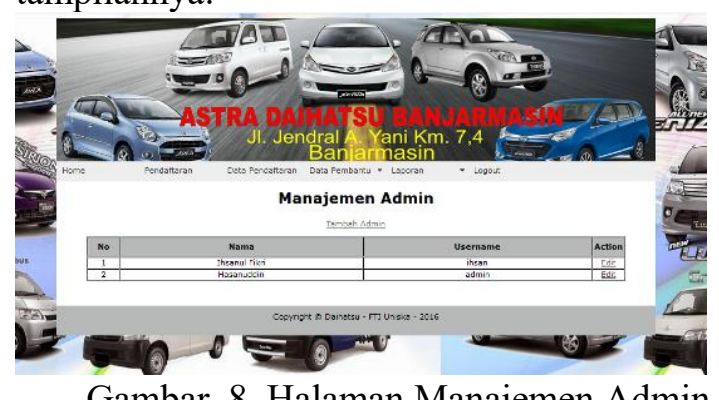

Gambar 8. Halaman Manajemen Admin

\section{g. Halaman Laporan Data Servis}

Pada halaman ini admin dapat melihat maupun memprint data servis. Print laporan data servis bisa harian bulanan maupun tahunan. Berikut tampilannya. 


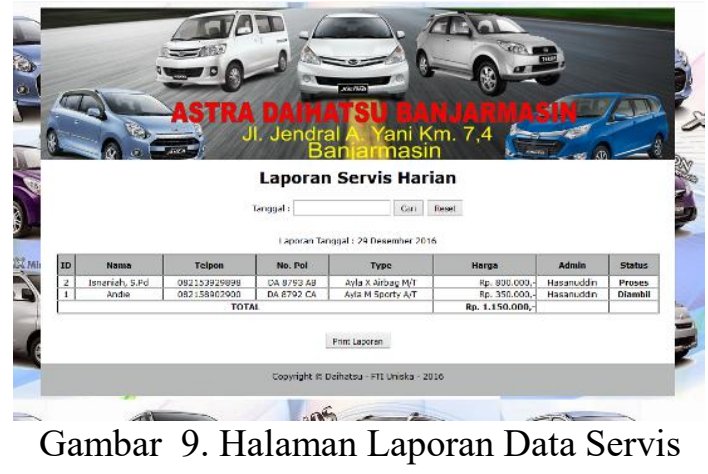

h. Logout

Apabila admin sudah selesai menggunakan aplikasi, sebaiknya admin harus memilih menu logout. Setelah admin memilih menu logout maka otomatis akan kembali ke halaman login. Menu logout juga berfungsi menghapus session dari masing-masing admin yang login, jadi lebih aman untuk meninggalkan aplikasi.

\section{KESIMPULAN}

Customer Care mempunyai arti yakni "Layanan Pelanggan", perusahaan memberikan pelayanan yang maksimal untuk mendapatkan respon yang baik dari pelanggan. Customer care adalah kunci kesuksesan perusahaan. Customer care mempunyai arti hampir sama dengan Customer Relationship Management (CRM), mempunyai arti strategi organisasi dalam mengelola hubungannya dengan pelanggan. Suatu perusahaan menjaga dan memberikan kualitas pelayanan yang terbaik kepada pelanggan, sehingga pelanggan merasa puas dengan pelayanan yang diberikan. CRM sebagai core business strategy yang mengintegrasikan proses internal serta fungsi-fungsi yang ada dalam perusahaan dengan jejaring eksternal untuk menciptakan dan memberikan manfaat kepada target pelanggan yang memberikan keuntungan.

Sms gateway merupakan suatu platform yang menyediakan mekanisme untuk mengirim dan menerima SMS dari peralatan mobile (HP, Smartphone, dan lain-lain). Sms gateway digunakan untuk menyebarkan pesan ke banyak nomor secara otomatis, cepat, dan terhubung langsung dengan database yang berisi nomornomor ponsel yang akan dikirimi SMS broadcast tersebut, sehingga secara otomatis sms akan tersebar tanpa harus mengetik sms satu per satu. Terdapat beberapa pengembangan dari aplikasi Sms gateway, diantaranya yaitu SMS Polling,
SMS on Demand, SMS Scheduller, SMS Massal, SMS Auto Replay. SMS Auto Replay merupakan salah satu jenis pengembangan dari Sms gateway yang dengan adanya fitur ini, maka setiap SMS yang diterima sistem akan dibalas secara otomatis oleh sistem (Tarigan, 2013). Berikut pada Gambar 2.1 akan disebutkan mekanisme kerja SMS Gateway.

Proses service dimulai dari pelanggan melakukan pendaftaran service mobil pada Service Advisor (SA), selanjutnya mobil diserahkan kepada mekanik dan bagian sparepart untuk pengecekan selanjutnya. Setelah proses service mobil selesai, maka dilanjutkan dengan proses pencucian mobil. Menurut informasi dari angket kepuasan pelanggan, pelanggan yang meninggalkan proses service tidak merasa puas dengan pelayanan service, karena petugas service seringkali lupa tidak melakukan konfirmasi secara langsung bahwa kendaraan telah selesai diservice. Hal ini seringkali terjadi dikarenakan tidak adanya sistem secara otomatis yang dapat melakukan konfirmasi secara langsung dari step posisi kendaraan yang diservice. Seharusnya setiap perubahan data status service akan di sampaikan langsung ke Handphone pelanggan melalui SMS. Jadi pelanggan dapat mengetahui sudah sampai dimana proses service mobilnya masing-masing.

Tujuan penelitian ini adalah agar mempermudah Service Advisor (SA) dalam menginput data service dan juga mempermudah penyampaian informasi data status service langsung ke masing-masing pelanggan

Pada Aplikasi Pendaftaran Servis ini terdapat halaman utama yaitu halaman administrator, halaman ini di kelola oleh admin yaitu Service Advisor (SA).

\section{REFERENSI}

[1] Peranginangin and Kasiman, Aplikasi WEB dengan PHP dan MySQL, Yogyakarta: ANDI, 2006.

[2] M. Subekti, Sistem manajemen Basis Data, Jakarta: Universitas Bina Nusantara, 1997.

[3] Andie, M. I. Firdaus and Hasanuddin, "Sistem Informasi Website Tracer Study di Universitas Islam Kalimantan (UNISKA) Muhammad Arsyad Al Banjari Banjarmasin," Al Ulum Jurnal 
Sains Dan Teknologi, vol. 4, no. 2, pp. 28-32, 2019.

[4] M. Rasyidan, Andie and M. I. Firdaus, "Perancangan Aplikasi Absensi Kelas Berbasis SMS Gateway," Al Ulum Jurnal

Sains Dan Teknologi, vol. 2, no. 1, pp. 52-57, 2016. 